\title{
CiNCUENTA AÑOS DE LA humanaE VitAE: \\ UNA MEDITACIÓN SOBRE EL SILENCIO Y EL DIÁLOGO DE LA IGLESIA CON LA EXPERIENCIA HUMANA DE LA SEXUALIDAD
}

Fifty Years of the Humanae Vitae: a Meditation on Silence and the Church's Dialogue with the Human Experience of Sexuality

Francisco Javier de La Torre Díaz *

RESUMEN: Los cincuenta años de la Humanae vitae muestran con claridad el desarrollo paulatino de una moral eclesial en la que cada vez se integran mejor las diversas voces de la Iglesia. Esta historia muestra una más profunda eclesiología de comunión centrada más en lo que une que en cuestiones secundarias muy debatidas, más en criterios que en normas, más basada y asentada en la experiencia humana que en principios abstractos.

PALABRAS-CLAVE: Humanae vitae. Diálogo. Silencio.

ABSTRACT: The fifty years of the Humanae vitae show clearly the gradual development of a moral in which the diverse voices of the Church are increasingly integrated. This story shows a deeper ecclesiology of communion centered more on what unites than on highly debated secondary issues, more on criteria than on norms, more based on human experience than on abstract principles.

KEYWORDS: Humanae Vitae. Dialogue. Silence.

* Universidad Pontificia Comillas, Madrid, España. 


\section{Introducción}

Humanae vitae es la encíclica de toda la historia más conocida, más co1 mentada y más contestada. Ha generado un debate como ninguna otra lo ha logrado. La bibliografía es imponente y llena estanterías enteras. El tema de la píldora y el papa fue portada en todos los diarios del mundo desde la revista Time a las hojas parroquiales. Las sucesivas conmemoraciones de las décadas han seguido generando comentarios y reflexiones aunque cada vez menores. Cincuenta años después en muchos países la conmemoración se está preparando en pequeños congresos y cenáculos sin demasiada relevancia pública mientras en otros parece reinar un cierto silencio que pretende hacernos mirar a otros lados que se consideran más importantes. ¿Qué es lo que ha ocurrido en estos temas para que se el paso de un cierto ruido a cierto silencio? ¿Qué es lo que hace que en la Iglesia ciertos debates se hagan centrales y se llenen de palabras y otros sean olvidados o dejados al margen?

En este artículo analizaremos esta cuestión a la luz de los cincuenta años de la Humanae vitae fijándonos en lo central de los debates en el concilio y en el postconcilio, en la comisión preparatoria de la Constitución Gaudium et Spes, en la comisión para el Estudio de la Población, en los comentarios a la Humanae vitae por parte de las Conferencias Episcopales, en el planteamiento de los tres últimos pontificados (Juan Pablo II, Benedicto XVI y Francisco) y en los dos Sínodos sobre la familia de 1980 y 2014.

El tema del silencio y la palabra tiene que ver con el modelo eclesial. A. Lehmkuhl, S.I. en 1901 escribió contra un profesor universitario que en la prensa tachó anónimamente a la moral de inmovilista: este es

"un asunto de la exclusiva competencia de la Iglesia...En ésta todo viene de arriba...y no hay sitio para el elemento democrático de la opinión pública... Tampoco el clero puede actuar si no es bajo las indicaciones del episcopado, e incluso los obispos están sometidos al poder supremo del papa de Roma de la misma manera que los simples fieles les están sometidos a ellos...Esta dependencia es la gloria de los católicos".

Pocos años después, Pío X en 1906 señaló que sobre la Iglesia:

“Esta sociedad es, por tanto, en virtud de su misma naturaleza, una sociedad desigual (ineguale); es decir, una sociedad compuesta de distintas categorías de personas: los pastores y el rebaño, esto es, los que ocupan un puesto en los diferentes grados de la jerarquía y la multitud de los fieles. Y estas categorías son de tal modo distintas unas detrás, que sólo en la categoría pastoral residen la autoridad y el derecho de mover y dirigir a los miembros hacia el fin propio de la sociedad; la obligación, en cambio, de la multitud no es otra que dejarse gobernar y obedecer dócilmente las directrices de sus pastores" (PÍO X, 1906). 
En una Iglesia piramidal donde la verdad está en la jerarquía hay poco espacio para la experiencia de los fieles y más si esa experiencia es la sexualidad. Toda doctrina emana de arriba hacia abajo y la escucha y el diálogo no entran. En estas páginas quiero describir cómo en nuestra Iglesia se ha ido introduciendo el silencio, la escucha, el debate y el diálogo en las cuestiones de moral sexual desde una óptica concreta y muy ilustrativa como es los debates sobre las decisiones conceptivas y anticonceptivas.

\section{El debate de los cardenales - 29 de octubre de 1964}

El 29 de octubre de 1964, en la Congregación General 112, se empezarán a discutir estos temas en el aula conciliar. En ese día se tuvieron 17 intervenciones. Las más relevantes fueron las siguientes y muestran un profundo debate y división de opiniones (DE LA TORRE, 2018, p. 115121). El Cardenal Ruffini inauguró la sesión:

Por respeto, no me extenderé aquí. Pero creo que debemos imitar a San Agustín, que no temía decir que los esposos que no usan cristianamente el matrimonio caen en el estupro y la prostitución. No tengamos miedo a decir la verdad. Y la verdad es que en este punto no hay nada nuevo que decir: la verdad católica fue ya bien clarificada en la Casti connubii de Pío XI y por el discurso de Pío XII a las comadronas en 1951. Repitamos aquello y dejemos este asunto. (DE LA TORRE, 2018, p. 115-116).

Estas palabras son todo un símbolo de una postura inmovilista: "hay que volver a san Agustín", "hay que decir la verdad", "la verdad la tenemos nosotros", "la verdad ha sido dicho por los pontífices anteriores, y nuestra tarea es callar y repetir lo dicho anteriormente".

El Cardenal Léger, el segundo orador, afirmó con claridad en un sentido muy distinto:

Ansiedades y dudas acerca del matrimonio se expresan en muchas regiones y por parte de personas de todas las condiciones. Los creyentes -incluso los más fervorosos- se ven sometidos a la presión cotidiana de dificultades; buscan soluciones que se hallen en consonancia con su fe, pero las respuestas que se les han dado hasta ahora no satisfacen a sus conciencias. Los pastores, especialmente los confesores, han llegado a sentir dudas e incertidumbres; en muchos casos no saben cómo pueden y deben responder a los fieles. Muchos teólogos ven cada vez más clara la necesidad de investigar de manera nueva y más profunda los principios fundamentales de la doctrina acerca del matrimonio (DE LA TORRE, 2018, p. 119).

El Cardenal Suenens, el tercero en intervenir, abogó por un tratamiento más coherente. 
El segundo trabajo de la Comisión [pontificia sobre la regulación de la natalidad] se sitúa en la línea del progreso científico y del conocimiento más ahondado de la ética natural. La Comisión deberá examinar si la doctrina clásica, sobre todo la de los manuales, tiene suficientemente en cuenta los nuevos datos de la ciencia actual. Se ha adelantado mucho desde Aristóteles, y hemos descubierto la complejidad de lo real donde lo biológico se interfiere con lo psicológico, lo consciente con lo inconsciente. Se descubren constantemente nuevas posibilidades, así como su poder de dirigir el curso de la naturaleza. De donde se deduce un conocimiento más profundo de la unidad del hombre, tanto en su ser en cuanto espíritu encarnado como en el dinamismo de toda su vida, unidad que es como el centro de la antropología tomista. De ello se sigue igualmente una apreciación más exacta de su poder razonable sobre el mundo que le está confiado. ¿Quién no ve que de este modo nos veremos quizá conducidos a unas investigaciones posteriores sobre la cuestión de lo que es "acorde o contrario a la naturaleza"? Sigamos los procesos de la ciencia. Os ruego, padres, que evitemos un nuevo "proceso Galileo". Con uno le basta a la Iglesia (AAS III/6, 57-59).

\section{Más adelante Máximos $I V$, patriarca de Antioquia:}

Seamos realistas; veamos el real desajuste que hay entre la doctrina oficial de la Iglesia y la práctica contraria de la inmensa mayoría de los cristianos. Muchos cristianos se ven obligados por este problema a vivir fuera de la ley de la Iglesia, lejos de los sacramentos, en una angustia constante. Y todo porque no encuentran una solución viable que les permita responder simultáneamente a dos imperativos hoy contradictorios: lo que les manda su conciencia de cristianos y lo que les exige su vida conyugal moral... Preguntémonos si en nuestras posiciones no somos tributarios de ciertas concepciones anticuadas, de nuestra propia psicología de solteros ajenos al problema, del peso de ciertas condiciones maniqueas que veían la obra de la carne como mala en sí y soportable únicamente porque conducía a la procreación. Pero ¿acaso puede ponerse la rectitud biológica como criterio de moralidad, independientemente de la vida del hogar, de su clima moral, conyugal y familiar y de los graves imperativos de la prudencia? Por otra parte, la exégesis actual nos hace reconsiderar algunos pasajes, como el de "creced y multiplicaos", y una nueva lectura del capítulo de Onán, base tradicional escriturística de la Iglesia para condenar las prácticas anticonceptivas. Por otra parte, ¿no nos llevaría nuestra sensibilidad ecuménica a establecer un diálogo con las iglesias separadas en esta materia? ¿Por qué replegarnos hacia nosotros mismos, cuando es un problema que afecta a toda la humanidad? (SIMÓN, 2004, p. 282).

Máximos IV Saigh llegó a preguntarse si, ante un incremento demográfico que condenaba a cientos de millones de personas a una miseria indigna y desesperanzada, a «un deprimente y antinatural callejón sin salida», eso era realmente la voluntad de Dios. También afirmó con rotundidad: «Francamente, ¿no habrá que revisar las posturas oficiales de la Iglesia en esta materia a la luz de nuestros conocimientos actuales: teológicos, médicos, psicológicos y sociológicos?»(ALBERIGO, 2007, p. 290). 
El Cardenal Ottaviani, a propósito de los debates sobre el papel de la conciencia de los esposos en las decisiones conceptivas, señaló con dureza:

He de decir que no me agradan las afirmaciones en las que se dice que los padres han de fijar el número de sus hijos. Esto es cosa inaudita en la doctrina secular de la Iglesia. ¿Qué quedaría del precepto «creced y multiplicaos»? Y no se diga que se contrapone al de «seréis dos en una sola carne». ¿Por qué oponer un mandamiento al otro? Y he aquí mi testimonio personal: soy el undécimo hijo de una familia de doce hermanos. En mi casa éramos pobres. Mi padre era un trabajador manual. Y nunca mis padres dudaron de la providencia. Mis padres creían en la palabra del Evangelio, que habla de los pájaros del cielo y los lirios del campo. Creían también en las afirmaciones de que hemos de preocuparnos ante todo del Reino de Dios y que todo lo demás se nos dará por añadidura. Creían en la frase del salmo que evoca a las familias cristianas fecundas y numerosas en torno a la mesa. Seamos prudentes. ¿Vamos a dar la impresión de que la Iglesia cambia de doctrina después de veinte siglos? ¿Acaso se ha errado hasta ahora? Seamos prudentes: no nos desviemos de la santa doctrina.

El esquema Ruffini-Ottaviani es claro: inspiración agustiniana, la Iglesia tiene la verdad, la Iglesia proclama la verdad, la verdad está recogida en las intervenciones de los papas anteriores, lo que hay que hacer es repetir estas expresiones y dejar a un lado los debates, la Iglesia no puede errar en su doctrina. A pesar de las dificultades, se puede cumplir la doctrina basados en la providencia y el esfuerzo ascético.

El esquema Léger-Suenens-Maximos IV parte de la realidad, de las inquietudes de los fieles, del desajuste con la doctrina, de la necesidad de profundizar y replantear las cuestiones a la luz de la experiencia y los conocimientos científicos, de la autocrítica (preguntémonos), del cuestionarse con las preguntas de los fieles, del reconocimiento de graves conflictos de valores en las parejas, de la apertura ecuménica, de la exégesis actual y percepción de la importancia del clima moral, conyugal y familiar.

Este debate es público, claro, realizado por personas de gran responsabilidad eclesial y centrado en una tensión entre el modelo teológico moral más jerárquico-deductivo-doctrinal y el modelo de comunión más inductivo-experiencial. La experiencia de los fieles llega al aula conciliar a través de los teólogos, los obispos y cardenales.

\section{El debate limitado en la elaboración de la constitución Gaudium et spes - 24 de noviembre de 1965}

Estas diferencias permanecieron todo el Concilio (DE LA TORRE, 2018, p. 122-136). El Concilio, como todos sabemos, no dio una respuesta concreta 
al tema de la anticoncepción y del control de natalidad. Pablo VI no quiso que sobre este tema se pronunciara el Concilio y se remitiera a la Comisión que estaba estudiando el tema, como bien aparece en la famosa nota 14 de Gaudium et Spes. El Concilio se limitó en ese magnífico número 50 de Gaudium et Spes a ofrecer unos criterios de discernimiento y formación de la conciencia a los cristianos y a instar a decidir en la pareja con responsabilidad y de común acuerdo. En la redacción de este número trabajaron varios teólogos morales y especialmente B. Häring.

Por eso, con responsabilidad humana y cristiana cumplirán su misión y con dócil reverencia hacia Dios se esforzarán ambos, de común acuerdo y común esfuerzo, por formarse un juicio recto, atendiendo tanto a su propio bien personal como al bien de los hijos, ya nacidos o todavía por venir, discerniendo las circunstancias de los tiempos y del estado de vida tanto materiales como espirituales, y, finalmente, teniendo en cuenta el bien de la comunidad familiar, de la sociedad temporal y de la propia Iglesia. Este juicio, en último término deben formarlo ante Dios los esposos personalmente. En su modo de obrar, los esposos cristianos sean conscientes de que no pueden proceder a su antojo, sino que siempre deben regirse por la conciencia, la cual ha de ajustarse a la ley divina misma, dóciles al Magisterio de la Iglesia, que interpreta auténticamente esa ley a la luz del Evangelio (GS, n. 50).

Pero, el 24 de noviembre de 1965, dos semanas antes de la clausura del concilio, interviene personalmente Pablo VI a través de una carta que lee el Cardenal Ottaviani, para que en la última reelaboración del texto de la Gaudium et Spes se tengan en cuenta una serie de aportaciones (DE LA TORRE, 2018, p. 126-127). La carta señalaba unos cambios que debían introducirse a petición del papa: «Os anuncio que el Augusto Pontífice desea que [...] es necesario informar a la comisión [...] la existencia de ciertos puntos que necesariamente deberán ser corregidos». El escrito contenía cinco Modos o enmiendas para dar continuidad en el concilio a las enseñanzas magisteriales de Pío XI y Pío XII (AA. VV., 1967, p. 105-109).

1) Debe condenarse la anticoncepción (artes conceptionales), además de la poligamia y el amor libre.

2) En la problemática del control de natalidad, a los esposos «no les es lícito ir por caminos que han sido condenados o sean condenados por el Magisterio».

3) Pide una alabanza de las familias numerosas.

4) Solicita una referencia explícita en las notas a Casti connubii y al discurso de Pío XII en 1951 a las comadronas.

5) También cree que debe tenerse en cuenta que los esposos, ante las dificultades matrimoniales, deben cultivar sinceramente la «castidad conyugal».

Ottaviani presenta estas aportaciones del Papa como «confirmación de la enseñanza precedente», causando un gran desánimo en los ámbitos más renovadores, que creen que sobra toda discusión ulterior.

¿Cómo podía pronunciarse el concilio acerca de una cuestión que el papa había dejado fuera de su competencia? ¿Cómo podía pronunciarse el concilio 
acerca de una cuestión que no había sido debatida en el aula conciliar? ¿Cómo podía pronunciarse el concilio cuando otro organismo nombrado por el papa estaba examinando el asunto? ¿Cómo podía presentar la subcomisión en el último momento, para ser votado, un texto en el que se había introducido un cambio tan radical? Si el concilio se pronunciaba al respecto, ¿no dejaría de tener sentido la Comisión Papal? (O’MALLEY, 2012, p. 382).

¿No implicaba eso que el tema dejaba de estar abierto? «Esa habría sido la gran victoria para la minoría, que, por supuesto, extrajo precisamente dicha conclusión. El cardenal Michael Browne, dominico irlandés, exclamó: Christus ipse locutus est («El propio Cristo ha hablado») (HEBBLETHWAITE, 1995, p. 397). El redactor de los modi fue probablemente fray E. Lio, que también redactó el esquema De Castitate, proyecto preconciliar que fue rechazado y que con estos modi en algunos puntos quiso reintroducir de nuevo. La intervención provocó una semana de crisis (DE LA TORRE, 2018, p. 127-130).

\section{El debate interdisciplinar en la Comisión para el Estudio de la Población y la natalidad - 24 de junio de 1966}

La Comisión creada por Juan XXIII y ampliada en sucesivas ocasiones por Pablo VI, concluyó su trabajo en junio de 1966 con división de opiniones. La Comisión escuchó voces plurales de los distintos ámbitos del saber y de distintas geografías. Fue un trabajo interdisciplinar e internacional enormemente rico y que fascinó a muchos. También se escucharon la voz de algunas parejas. La mayoría de los teólogos se inclinaban hacia soluciones abiertas. Solo una minoría consideraba que la doctrina tradicional no podría nunca cambiarse. El 24 de junio de 1966 se realizaron tres preguntas en la Comisión de obispos. La primera era si la contracepción era lícita en sí misma o intrínsecamente nociva. La votación fue: 2 «sí», 1 «sí con reserva», 3 abstenciones y 9 «no» (y un ausente). Luego se pasó a la redacción de los dos textos. Los trabajos terminaron el 25 de junio de 1966. El informe final, ratificado por la Comisión, fue presentado al Papa por el cardenal Döpfner y por el padre H. de Riedmaatten, secretario general de la Comisión. El presidente de la comisión, el cardenal Ottaviani, se había negado a hacerlo. Más tarde se supo que el cardenal Ottaviani sometió otro documento al papa.

El documento discutido y aprobado fue entregado al papa. El cardenal Ottaviani entregó otro documento ni conocido ni discutido ni aprobado por la Comisión. Probablemente, fue el documento de John Ford, SJ, sobre las consecuencias que sufriría la autoridad papal si se abandonaba la Casti connubii. El problema no eran los anticonceptivos. Lo que preocupaba era el cuestionamiento y la valoración de la autoridad papal. Admitir que la 
Iglesia se hubiera equivocado durante siglos debilitaría su enseñanza y autoridad.

Posteriormente en la primavera de 1967, el papa nombraría una Comisión de ocho teólogos, la mayoría afines y del gusto del papa, para elaborar la encíclica: Visser, Martelet, Colombo, Ottaviani, Zalba, etc. En esta Comisión ya no hubo debate y se dejaron a un lado las conclusiones de la mayoría de la Comisión y, en gran parte, la experiencia de los fieles.

\section{El debate integrador de las conferencias episcopales de 1968}

La Humanae Vitae rechaza el documento de la mayoría de la Comisión y dedica una serie de números (n. 19-30) a dar unas orientaciones pastorales claras a esposos, sacerdotes, teólogos, médicos, investigadores para que se cumpla la encíclica, aunque parezca "a los ojos de muchos difícil e incluso imposible en la práctica".

El realismo y la prudencia pastoral de los obispos se hicieron presentes nada más ser publicada la $H V$. Más de cuarenta Conferencias Episcopales hicieron eco de la encíclica (ZALBA, 1971). La mayoría de los episcopados lamentan que el debate se haya centrado en los medios anticonceptivos y no se hayan tenido en cuenta muchos de los elementos positivos de la HV. El jesuita Marcelino Zalba (1971, p. 186-187) identifica cuatro tipos de documentos de las conferencias episcopales:

1) Pequeño grupo: apenas desarrollan el argumento de la encíclica, porque entra incidentalmente en un plan más amplio (Senegal). A veces lo proponen con pleno reconocimiento y adhesión (CELAM).

2) Grupo numeroso: apoyo sin paliar en nada su punto más difícil. A favor, motivos de fe y ascética cristiana (Colombia, España, México, India, Polonia, Alemania Oriental).

3) Grupo poco numeroso: preocupado sensiblemente por la situación difícil de los fieles y por impedir que se rebelen contra la declaración: hablan de la conciencia, refieren a lo más general, recuerdan el error posible del magisterio, los conflictos de deberes (canadiense, francesa).

4) Expresan la doctrina y se preocupan por la pastoral práctica, las situaciones individuales o socializadas, los silencios discretos para no convertir en pecado formal lo que habría sido solo pecado material, la condición de cada fiel en el tribunal de la penitencia (Italia, Inglaterra y Suiza).

La mayoría de los episcopados señalan la necesidad de continuar el estudio y el diálogo, lo cual es señal de que no se considera un tema cerrado. 
El jesuita E. Hamel, en su detallado análisis de los diversos documentos de las conferencias episcopales, concluye que las conferencias episcopales se pronunciaron entre otras cosas por su deber pastoral para con los fieles ante sus inquietudes y dificultades. Por eso pretendieron varias cosas: 1) Aportar un complemento doctrinal, enmarcándolas en una síntesis superior, donde encuentran su lugar la doctrina tradicional de la conciencia cristiana, sus deberes y sus funciones y los principios para sopesar la culpabilidad. 2) Ilustrar en forma explícita y completar las orientaciones pastorales, que por fuerza se mantenían en un plano general en la encíclica, descendiendo a los datos más concretos, a los problemas nacionales o locales. 3) Dentro del respeto a la conciencia individual, intentan una mejor comprensión de la encíclica, para conservar la paz del espíritu o para reencontrarla. 4) Proporcionar algunas orientaciones a los sacerdotes y teólogos en relación al régimen de la propia conciencia y la enseñanza de la doctrina de la Iglesia (HAMEL, 1969, p. 115-117).

En Estados Unidos, más de 600 teólogos morales firmaron una declaración crítica con la eclesiología y metodología de la HV. Entre los firmantes estaban teólogos de la altura de Charles Curran, Bernard Häring, David Tracy o Richard McBrien. En septiembre de 1968, un grupo de teólogos europeos firmaron otra declaración crítica con la $H V$. Entre los firmantes se encontraban J. M. Aubert, A. Auert, T. Beemer, F. Böckle, W. Bulst, P. Fransen, J. Groot, L. Janssens, R. van Kessel, C. Robert, P. Schoonenberg,etc (MCCORMICK 1993, p. 7). Karl Rahner también expresó sus reservas en varias publicaciones.

\section{El debate en el Sínodo de los obispos de 1980}

En el sínodo ordinario de los Obispos de 1980 varios obispos, como J. Quinn, arzobispo de San Francisco, B. Hume, arzobispo de Westminster, y J. Jullien, obispo de Beauvais, pidieron una cuidadosa reconsideración de las soluciones ofrecidas por la $H V$.

En la presentación del Instrumentum laboris J. Ratzinger invitará a formular una palabra «crítica y profética» contra las ideologías alienantes de la persona y a defender la $H V$ con nuevos argumentos. Había una cierta conciencia de que el lenguaje y los argumentos de la $H V$ debían mejorarse.

J. R. Queen, arzobispo de San Francisco, subrayó los problemas de recepción eclesial que estaba teniendo la $H V$. En nombre de su conferencia episcopal indicó que existían tres posturas ante la $H V$ : silencio, asentimiento y disenso. La otra posibilidad, todavía no suficientemente explorada, era la 
de una exposición doctrinal mucho más amplia, orgánica y sintética que la realizada hasta entonces. En otra intervención informó de que el $80 \%$ de las mujeres católicas usaban anticonceptivos en USA, y que solo el 29\% de los sacerdotes consideraban inmoral tal práctica. El arzobispo planteó con claridad los problemas de recepción de la $H V$.

El obispo de Lausana-Ginebra, G. Bullet, recordó que el Sínodo no podía limitarse a repetir doctrinas conocidas, sino que había que evaluarlas para posibilitar su progreso homogéneo. Planteó la necesidad de contemplar la situación real de la familia para proponer una moral sexual y familiar creíble en el presente.

En la sesión de clausura Juan Pablo II enfatizó el carácter profético de la $H V$ y advirtió sobre la necesidad de que la gradualidad pastoral no llevara a dar por buenas «exégesis relativizantes de la ley divina». En la Exhortación apostólica postsinodal Familiaris consortio, a pesar de reconocer que su doctrina es "difícil de comprender" ( $F C$, n. 30), invita a los teólogos a colaborar con el magisterio y a una «adhesión convencida al Magisterio, que es la única guía auténtica del Pueblo de Dios», y a que consideren la «relación íntima que existe entre la doctrina católica sobre este punto y la visión que propone la Iglesia. Dudas o errores en el ámbito matrimonial o familiar llevan a una ofuscación grave de la verdad integral sobre el hombre, en una situación cultural que muy a menudo es confusa y contradictoria» $(F C$, n. 31).

Juan Pablo II señala la «singular importancia que tiene en este campo la unidad de juicio moral y pastoral de los sacerdotes: tal unidad debe ser buscada y asegurada cuidadosamente, para que los fieles no tengan que sufrir ansiedades de conciencia» $(F C, \mathrm{n}$. 34). «La pedagogía concreta de la Iglesia debe estar siempre unida y nunca separada de su doctrina» $(F C, \mathrm{n} .33)$, y por eso recuerda la frase tan conocida de Pablo VI en $H V$ : «No menoscabar en nada la saludable doctrina de Cristo es una forma de caridad eminente hacia las almas» (n. 29). Con el Magisterio de Juan Pablo II, la opción fue asegurar cuidadosamente la unidad de juicio.

\section{La limitación y reformulación del debate: Juan Pablo II}

Juan Pablo II al inicio de su pontificado, durante más de cuatro años, en las audiencias de los miércoles desde septiembre de 1979 a noviembre de 1984 desarrolló unas catequesis que en su conjunto forman lo que se ha llamado la teología del cuerpo. El sexto ciclo de catequesis, entre julio y noviembre de 1984, lo dedicó al amor y la sexualidad en una relectura original de la $H V$. Con un lenguaje más bíblico y más personalista ilumina la sexualidad del cuerpo dentro del plan de salvación. 
Pocos años más tarde, y en un lenguaje bien distinto, dirigiéndose al II Congreso Internacional de Teología Moral el 12 de noviembre de 1988, señaló con claridad y cierta dureza:

Pablo VI, calificando el acto contraceptivo como intrínsecamente ilícito, ha pretendido enseñar que la norma moral es tal que no admite excepciones: ninguna circunstancia personal o social ha podido jamás, ni puede, ni podrá hacer en sí mismo ordenado un semejante acto... No se trata, en efecto, de una doctrina inventada por el hombre; ella ha sido inscrita por la mano creador de Dios en la naturaleza misma de la persona humana y ha sido confirmada por él en la revelación. Ponerla en discusión, por tanto, equivale a negar a Dios mismo la obediencia de nuestra inteligencia. Equivale a preferir el resplandor de nuestra razón a la luz de la Sabiduría Divina, cayendo, así en la oscuridad del error y acabando por hacer mella en otros puntos fundamentales de la doctrina cristiana ( $H V, n$. 5).

En el discurso afronta el tema de la conciencia en relación con el Magisterio:

Ya que el Magisterio de la Iglesia ha sido instituido por Cristo el Señor para iluminar la conciencia, apelar a esta conciencia precisamente para contestar la verdad de cuanto enseña el Magisterio comporta el rechazo de la concepción católica de dicho Magisterio y de la conciencia moral. Hablar de la inviolable dignidad de la conciencia, sin ulteriores especificaciones, conlleva el riesgo de graves errores... No se puede decir que un fiel ha realizado una diligente búsqueda de la verdad si no tiene en cuenta lo que el Magisterio enseña; si, equiparándolo a cualquier otra fuente de conocimiento, él se constituye en su juez; si, en la duda, sigue más bien su propia opinión o la de los teólogos, prefiriéndola a la enseñanza cierta del Magisterio $(H V$, n. 4).

Desde estas premisas deontológicas y normativas se comprende el rol del teólogo y el discernimiento de los fieles de las enseñanzas de la Iglesia. La doctrina no puede ser cuestionada, pues existe una constante enseñanza de la Tradición y del Magisterio. El disentimiento es un conflicto con la ley de Dios y guía por un falso camino. Por eso esta doctrina no está abierta a la libre discusión.

Con el magisterio de Juan Pablo II se refuerza el papel del magisterio pontificio a través de diversos documentos: la instrucción Donum veritatis, sobre la vocación del teólogo (1990); la encíclica Veritatis splendor (1993); el motu proprio «Apostolos suos» (1998), que regula la capacidad magisterial de las Conferencias episcopales; y el motu proprio «Ad tuendam fidem» (1998). Ya en Donum veritatis, la Congregación para la Doctrina de la Fe señala que «las opiniones de los fieles no pueden, pura y simplemente, identificarse con el sensus fidei», debido a que las ideas del pueblo de Dios "pueden sufrir fácilmente el influjo de una opinión pública manipulada por los modernos medios de comunicación». La consecuencia es que el creyente «puede tener opiniones erróneas, porque no todos sus pensamientos proceden de la fe» (n. 35). Parece como si solo el magisterio ayudara a permanecer en la verdad y garantizara "desde arriba" y jerárquicamente la 
unidad de la Iglesia. Los límites sólo los tiene la experiencia de los fieles y la reflexión de los teólogos.

Desde aquí se comprende el modo de acompañar y acercarse del Magisterio a las dificultades de los esposos que plantea Juan Pablo II en su Mensaje al Congreso sobre Regulación de la Fertilidad, 22 de febrero de 1988:

La Iglesia es consciente de las diversas dificultades que pueden encontrar los esposos, sobre todo en el actual contexto social, no solo en la aplicación, sino también en la comprensión de la norma moral que les concierne. Como madre, la Iglesia se acerca a las parejas que tienen dificultades para ayudarles; pero lo hace recordándoles que el camino para hallar la solución a sus problemas no puede menos de pasar por el respeto pleno a la verdad de su amor. "No menoscabar en nada la saludable doctrina de Cristo - decía Pablo VI- es una forma de caridad eminente hacia las almas" (HV, n. 29).

El acercamiento del Magisterio es un simplemente recordar y ayudar a comprender la norma moral. Este modelo ha sido asumido predominantemente por los Pontificios Institutos Juan Pablo II para estudios del matrimonio y la familia, tan presentes en muchas diócesis, especialmente en el mundo iberoamericano y que se han adueñado durante años de la "exclusividad ortodoxa". Una cierta uniformidad ha empobrecido la riqueza católica en estos temas en unos temas donde la experiencia de los fieles era muy rica y diversa.

Además en este período hay un claro "silencio oficial" con respecto a las orientaciones de las Conferencias Episcopales de 1968. Estas orientaciones no aparecen, por ejemplo, en el Instrumentum laboris de 1980, en las discusiones en el aula y en la exhortación postsinodal del Sínodo sobre la familia.

Por otro lado, durante estos años fue clara la importancia de la aceptación sin fisuras de la $H V$ como criterio para ser promovido al episcopado. La doctrina de la $H V$ se volvió prácticamente indiscutible en muchos ámbitos eclesiales.

El papa Wojtyla, más allá de una cierta renovación del lenguaje, los conceptos y argumentaciones fundamentales, desea reafirmar la doctrina aunque es consciente de que el mundo ha cambiado enormemente, y en especial el mundo de la juventud. Lo que muchos se preguntan es que si el mundo ha cambiado enormemente en su vivencia de la sexualidad y si la finalidad procreativa y la «misión» procreativa son subrayadas con claridad, no es este un planteamiento idealista de la entrega, de la donación y de la castidad lejano de los contextos y condiciones reales de la mayoría de los fieles.

Lo cierto es que Juan Pablo II busca recuperar cierta preeminencia pública de la Iglesia a través de propuestas claras de verdades no negociables. La Iglesia debe ofrecer a todos los seres humanos una clara visión de lo 
humano. K. Wojtyla quería para la Iglesia mayor visibilidad pública y mayor relevancia social. Esta convicción le llevó en algunos temas, a asumir una cierta rigidez y claridad en las aplicaciones concretas de la moral de la persona (moral sexual, bioética, moral familiar). Esto no implica su indudable grandeza por su papel político en los últimos años de la guerra fría, sus múltiples viajes apostólicos a todo el mundo que hicieron más católica a la Iglesia, el valor de sus encuentros con otros líderes religiosos, su imponente magisterio social (Laborem exercens, Sollicitudo rei socialis, Centesimus annus) y su honda reflexión espiritual sobre la misericordia y el sufrimiento (Redemptor hominis, Dives in misericordia, Dominum et vivificantem, Salvifici doloris) (DE LA TORRE, 2018, p. 220-221).

Pero la realidad es que hubo poco debate y diálogo en estos años sobre la anticoncepción y la regulación de la natalidad. Algunos teólogos fueron sancionados duramente por sus posturas en la anticoncepción. Únicamente algunas voces autorizadas decían lo que pensaban. Entre ellas hay que destacar la del cardenal Martini:

Lo más triste es que la encíclica es, en parte, culpable de que muchos ya no tomen más en serio a la Iglesia como interlocutora o maestra. Pero sobre todo a los jóvenes de nuestros países occidentales ya casi ni se les ocurre acudir a representantes de la Iglesia para consultarlos en cuestiones atinentes a la planificación familiar o la sexualidad. Debo admitir que la encíclica Humanae vitae ha suscitado también un desarrollo negativo. Muchas personas se han alejado de la Iglesia, y la Iglesia se ha alejado de los hombres. Se ha producido un gran perjuicio... Es en cierto modo trágico que la Iglesia se haya alejado tanto de los afectados por estas cuestiones y de los que buscan respuestas para ellas (MARTINI, 2008, p. 141).

\section{Benedicto XVI la apertura de cierto debate - 17 de marzo de 2009}

Joseph Ratzinger siempre buscó nuevas maneras de presentar el contenido esencial de la HV. Ya como cardenal, dijo en 1995 que «naturalmente, tenemos la obligación de preguntarnos siempre si nuestras posiciones tienen o no un fundamento. Si la respuesta es positiva, es necesario encontrar el modo más convincente de expresar nuestro pensamiento. Para abordar el tema de la anticoncepción es imprescindible darse cuenta de que sus presupuestos han cambiado. [...] El esfuerzo por lograr una mayor comprensión prosigue ininterrumpidamente. Por esta razón diría que la encíclica tiene consistencia, aunque las motivaciones y la visión antropológica deben ser sometidas a un ulterior examen» (RATZINGER, 1995, p. 122-123).

En 1996 se publica una conversación del periodista Peter Seewald con el cardenal Ratzinger, en el que señala que no se puede abordar el tema de 
los anticonceptivos desde una "casuística individual». Para realizar una valoración adecuada de este asunto hay que «conocer primero cuáles son las grandes intenciones que la Iglesia tiene a la vista», recuperar «tres grandes opciones fundamentales» (una actitud positiva hacia el niño -cada hijo es una bendición de Dios y no es una carga-, el nexo íntimo que hay entre sexualidad y procreación y que los problemas morales solo se resuelven moralmente cambiando el modo de vida -no hay que valerse solo de la técnica o la química para buscar soluciones-). Finalmente, el papa reconoce que es importante «poner más de relieve qué sentido tienen las objeciones de la Iglesia, porque tal vez no siempre sus formulaciones son afortunadas». El papa comienza a plantear una hermenéutica un poco más amplia a la hora de abordar estos temas.

El papa Benedicto XVI, el 10 de mayo de 2008, en un congreso internacional sobre la actualidad de la $H V$, dijo: «La palabra clave para entrar con coherencia en sus contenidos sigue siendo el amor». Los principios de la Humanae vitae siguen vigentes. El papa señala una serie de criterios en una «cultura marcada por el predominio del tener sobre el ser»: defender la dignidad de la persona ante un ejercicio de la sexualidad que «se transforma en una droga que quiere someter al otro a los propios deseos e intereses, sin respetar los tiempos». Para el papa, el sí genuino, pronunciado y vivido en la reciprocidad, permanece «siempre abierto a la vida». Por eso «es urgente redescubrir una alianza que siempre ha sido fecunda». En cambio, «ninguna técnica mecánica puede sustituir el acto de amor que dos esposos se intercambian como signo de un misterio más grande, en el que son protagonistas y partícipes de la creación» (BENEDICTO XVI, 2008, p. 27-28). Siguiendo al Concilio Vaticano II, afirma el papa que todo acto conyugal debe quedar abierto a la vida (MIFSUD, 2012, p. 457). Habla de reciprocidad abierta, de alianza fecunda. Hay una perspectiva más amplia y menos centrada en los actos concretos.

El 17 marzo de 2009, en su viaje a Camerún, sus respuestas a unas preguntas realizadas por un periodista en el avión provocaron una serie de críticas internacionales pues el papa afirmó que los métodos de control de natalidad no resolvían el problema del sida, sino que, "por el contrario, agudizan el problema». Benedicto XVI dijo que el sida «no se puede resolver con eslóganes publicitarios ni con la distribución de preservativos». «La única vía eficaz para luchar contra la epidemia es la humanización de la sexualidad», «una renovación espiritual», destinada «a sufrir con los sufrientes». Francia, Alemania y la ONU calificaron la declaración y la calificación de irresponsable y peligrosa. El Vaticano intervino señalando que el papa había querido subrayar que la confianza en los anticonceptivos era una distracción ante la necesidad de una educación adecuada en la conducta sexual. Todos sabemos que no se «soluciona el problema» si solo se «mandan» por avión toneladas de preservativos. 
Pero que no se solucione solo con preservativos no implica que no tengamos que reconocer la eficacia del preservativo usado de modo correcto. Esta controversia levantó de nuevo la reflexión sobre el uso del preservativo en casos de sida (DE LA TORRE, 2018, p. 226-232). El obispo alemán Hans-Joschen Jaschke, el sudafricano Kevin Dowling, el cardenal Carlo Maria Martini, el cardenal Dionigi Tettamanzi, el teólogo de la Casa Pontificia George Cottier, monseñor Jacques Suadecau, miembro del Pontificio Consejo para la Familia, se declararon partidarios. También importantes teólogos morales, como los norteamericanos J. Keenan, L. Cahill, K. Kelly y John Fuller, el africano B. Bujo o el alemán M. Rhonheimer. Además, a los pocos meses de su pontificado, el propio Benedicto XVI encargó al presidente del Pontificio Consejo para la Salud, el cardenal Javier Lozano Barragán, la formación de una comisión formada por científicos y teólogos para que se estudiara el tema. El problema no parecía estar tan claro. Algunos documentos católicos de alto nivel ya habían reconocido la eficacia del preservativo (JUSTICIA Y PAZ SUIZA, 1998, p. 223). Otros textos, como la Declaración de la Comisión administrativa de la Conferencia Episcopal Norteamericana y su anexo, habían abierto, desde hacía algunas décadas, una serie de consideraciones de apertura desde el principio del mal menor, después de proponer y ser rechazada la vida en castidad a la persona.

En 2010, en el libro Luz del mundo, afirmó que «en el caso de los hombres dedicados a la prostitución, para quienes la anticoncepción no es un asunto central, los métodos de control de natalidad no constituyen una solución inmoral [...]; se justifica que los utilicen con el propósito de reducir el peligro de infección» (p. 132).

Podrá haber casos fundados de carácter aislado, por ejemplo cuando un prostituido utiliza un preservativo, pudiendo ser esto un primer acto de moralización, un primer acto de responsabilidad a fin de desarrollar de nuevo una conciencia de que no todo está permitido y de que no se puede hacer todo lo que se quiere (BENEDICTO XVI, 2010, p. 132).

«Hay ciertas categorías de personas que deben usarlos, como los "gigolós"». ¿No está la Iglesia católica fundamentalmente en contra de la utilización de los preservativos? «No los ve, por supuesto, como una solución real y moral».

«Centrarse solo en anticonceptivos significa banalizar la sexualidad. Esta banalización representa la peligrosa razón por la que muchas personas han dejado de ver en la sexualidad la expresión de su amor, para ver tan solo una suerte de droga que asumen por sí mismos» (p. 132). El papa aplica aquí sin dudas la prioridad de la totalidad sobre la parte, del mal menor y del no hacer daño a nadie, especialmente si es la persona a la que se quiere o con la que se convive.

El papa también realiza en el libro una valoración de la $H V$ :

Las perspectivas de la $\mathrm{HV}$ siguen siendo válidas, pero otra cosa es encontrar caminos humanamente practicables -asegura el papa-. Creo que 
habrá siempre minorías íntimamente convencidas de la exactitud de esas perspectivas y que, viviéndolas, quedarán plenamente satisfechas, de modo que podrán ser para otros un fascinante modelo a seguir. Somos pecadores (BENEDICTO XVI, 2010).

Pero no deberíamos asumir este hecho como una instancia contra la verdad, cuando esa alta moral no es vivida. Deberíamos buscar hacer todo el bien posible y apoyarnos y soportarnos mutuamente. Expresar todo esto también desde el punto de vista pastoral, teológico y conceptual, en el contexto de la actual sexología e investigación antropológica, es una gran tarea a la que es necesario dedicarse más y mejor (BENEDICTO XVI, 2010).

Llama la atención el reconocimiento «explícito» del papa de que el modelo a seguir propuesto por la $\mathrm{HV}$ es comprendido y vivido por «minorías íntimamente convencidas».

Benedicto XVI, en febrero de 2013, en una nueva excepción al principio general, autorizó en los hospitales católicos alemanes el uso de la píldora anticonceptiva de urgencia, conocida como «píldora del día siguiente», en mujeres víctimas de violación, a raíz del escándalo en torno a una joven que no fue atendida en dos clínicas de Colonia tras sufrir abusos sexuales. El cardenal Joachim Meissner, arzobispo de Colonia, declaró que la decisión de autorizar este uso de anticonceptivos fue consensuado con la Congregación para la Doctrina de la Fe y la Academia de la Vida ${ }^{1}$.

En 2016, como papa emérito, en su libro Últimas conversaciones con Peter Seewald, reflexiona sobre el pasado:

La Humanae vitae fue para mí, en mi situación de aquella época y en el contexto del pensamiento teológico en que me encontraba, un texto difícil. Era indudable que en ella se hacían afirmaciones esencialmente válidas, pero en aquel entonces el modo de argumentación no nos resultó satisfactorio, tampoco a mí. Yo busqué una perspectiva antropológica más abarcadora. De hecho, Juan Pablo II completó el planteamiento iusnaturalista de la encíclica mediante una visión personalista (BENEDICTO XVI, 2016, p. 199).

Tres críticas aparecen en el texto: fue un texto difícil, tiene un modo de argumentación no satisfactorio y se basa en una antropología poco abarcadora. Su talante intelectual le hace abordar los temas de un modo más genérico y amplio. Le preocupa la cultura tecnológica y la manipulación de la vida, la cerrazón al amor y a la vida de las parejas. Además cuando llegó a ser papa, tuvo el coraje de ir a lo más fundamental en los temas morales, subrayando ante la $H V$ la necesidad de una hermenéutica del amor y una apertura, en un sentido amplio, a la vida. Con su pontifica-

\footnotetext{
${ }^{1} \mathrm{http}: / /$ www.periodistadigital.com/religion/mundo/2013/02/21/los-obispos-alemanes-autorizan-la-pildora-del-dia-despues-en-caso-de-violacion-iglesia-religion-meisner-alemania.shtml; http:// www.dw.de/cardenal-autoriza-la-p\%C3\%ADldora-del-d\%C3\%ADa-despu\%C3\%A9s-en-caso-de-violaci\%C3\%B3n/a-16570671.
} 
do, por lo tanto, se ha reconocido el principio del mal menor en algunos casos, el seguimiento minoritario por parte de los católicos, la necesidad de establecer un acercamiento menos centrado en los actos y la búsqueda de una antropología más abarcadora.

\section{Papa Francisco: escuchas, diálogos y silencios}

A los pocos meses el papa Francisco, en la entrevista concedida al P. Spadaro, de la Civiltà Cattolica, afirma claramente:

No es necesario estar hablando de estas cosas sin cesar, no podemos seguir insistiendo solo en cuestiones referentes al aborto, al matrimonio homosexual o al uso de anticonceptivos». «Yo no he hablado mucho sobre estas cosas, y me lo han reprochado. Pero cuando se habla de ello hay que hablar en un contexto. El parecer de la Iglesia, por lo demás, es bien conocido, y yo soy hijo de la Iglesia, pero no es necesario hablar al respecto constantemente (SPADARO, 2013).

El motivo de fondo de esta actitud, se enraíza en planteamientos muy sólidos:

Las enseñanzas de la Iglesia, sean dogmáticas o morales, no son todas equivalentes. Una pastoral misionera no se obsesiona por transmitir de modo desestructurado un conjunto de doctrina para imponerlas insistentemente. El anuncio misionero se concentra en lo esencial, en lo necesario, que, por otra parte es lo que más apasiona y atrae, es lo que hace arder el corazón, como a los discípulos de Emaús (SPADARO, 2013).

Tenemos, por tanto, que encontrar un nuevo equilibrio, porque de otra manera el edificio moral de la Iglesia corre el peligro de caer como un castillo de naipes, de perder la frescura y el perfume del Evangelio. La propuesta evangélica debe ser más sencilla, más profunda e irradiante. Solo de esta propuesta surgen luego las consecuencias morales (SPADARO, 2013).

Para el papa es claro que no hay que hablar mucho de anticoncepción. Esto se debe a que hay que ir a lo esencial pues no todas las enseñanzas son iguales. En la entrevista el P. Spadaro le pregunta sobre la $H V$ :

Todo depende -responde el papa- de cómo sea interpretado el texto de $\mathrm{Hu}$ manae Vitae. El propio Pablo VI, hacia el final, recomendaba a los confesores mucha misericordia y atención a las situaciones concretas. Pero su genialidad fue profética, pues tuvo el coraje de ir contra la mayoría, de defender la disciplina moral, de aplicar un freno cultural, de oponerse al neomalthusianismo presente y futuro. El tema no es cambiar la doctrina, sino ir a fondo y asegurarse de que la pastoral tenga en cuenta las situaciones de cada persona y lo que esa persona puede hacer. También de eso se discutirá en los preliminares del sínodo (SPADARO, 2013).

Lo primero que reflejan estas palabras primeras es el subrayado de la misericordia, de la escucha y la atención a los contextos concretos, a las personas concretas. Con la exhortación apostólica Evangelii gaudium, 
Francisco configura el marco adecuado para hacer una "nueva" teología moral que reformula la tensión entre el silencio, el diálogo y la palabra: hay que poner en el centro el Evangelio ( $E G$, n.11, 277), no insistir en lo secundario $(E G, \mathrm{n} .34)$, tener pocos mandados (no cargar con demasiados preceptos) (EG, n. 43), mantener una proporción adecuada en lo moral (algo orgánico) (n. 38), mantener equilibrios entre lo personal y lo social, comprender que hay una jerarquía de verdades morales $(E G, n$. 36). Esto supone escuchar, acompañar, no imponer, alentar crecimientos, comprender desde los pobres y ser misericordioso. En este horizonte es importante no gastarnos en la Iglesia en confrontaciones estériles, que no haya "más guerra entre nosotros" (EG, n. 98-101).

\section{a) El pueblo de dios es preguntado por primera vez}

El papa Francisco tuvo el coraje de preguntar antes del Sínodo por la anticoncepción y la recepción de la $H V$. Asociaciones y grupos de fieles contestaron a la encuesta que el papa Francisco hizo llegar para preparar la III ${ }^{a}$ Asamblea Extraordinaria del Sínodo de los Obispos sobre la familia que tuvo lugar en octubre de 2014. Una consulta al pueblo de Dios en estos temas no se había hecho nunca por el Magisterio.

La conferencia episcopal alemana, recogiendo las experiencias de muchos fieles de diferentes diócesis, reconoce que la $H V$ sólo es conocida por la generación más mayor y ha sido reducida a la prohibición de los métodos artificiales. Sin embargo, la doctrina por la cual los padres deben considerar las condiciones físicas, económicas, psicológicas y sociales a la hora de tener hijos encuentra un amplio consenso. La gran mayoría de los católicos cree también que el matrimonio debe estar abierto a la concepción y que en su proyecto de vida una buena vida, la familia con los niños tiene un papel muy importante.

La distinción entre los métodos anticonceptivos naturales y artificiales y la prohibición de utilizar estos último, es rechazada por la mayoría de los católicos y prácticamente ignorada. Para la mayor parte de los católicos, la paternidad responsable comprende también la elección del método apropiado, seleccionado de acuerdo a criterios de seguridad, practicidad y tolerancia física. La distinción entre métodos anticonceptivos y los métodos que impiden la implantación del óvulo fecundado, es algo que tiene mayor consenso. El aborto es rechazado por la mayor parte de los católicos (...) «Sin embargo, la mayoría de los católicos rechazan la doctrina de la Iglesia según la cual, todos los aspectos de la sexualidad humana deben tener en cuenta en toda relación sexual y por lo tanto todo acto conyugal hecho intencionalmente infértil, es en sí mismo inmoral» (cf. HV, n. 14). Una minoría, inferior al 3\% se inclina a favor de los métodos de control de natalidad natural y los practica por convicción personal, aunque a menudo también lo hace por motivos de salud (...) Las respuestas recibidas de las diócesis, dicen unánimamente que la utilización de métodos artificiales para el control de natalidad no es juzgada como un pecado y por lo tanto no es materia de confesión. Más bien, la cuestión de la culpa y el pecado se presenta con un 
mayor análisis respecto de la relación entre los dos miembros que componen la pareja. Son considerados como pecado la infidelidad, la falta de amor o la falta de respeto (CENTRO TEOLÓGICO MANUEL LARRAÍN, 2014, p. 23-24).

Los obispos belgas reconocen que las posiciones de la $H V$

han hecho alejarse a muchas personas de edad en la Iglesia, mientras que muchos jóvenes no tienen ningún conocimiento de estas posiciones...Muchos desean que la Iglesia modifique su punto de vista al respecto y avanzan muchos argumentos. Estos mismos encuestados emiten al mismo tiempo críticas sobre la banalización de la sexualidad en nuestra sociedad...La diferencia entre métodos naturales y contracepción artificial está cuestionada así como las diferentes evaluaciones morales al respecto (...) Algunos piden que la $H V$ se mantenga más bien como horizonte o ideal (...) Se observa un abismo profundo entre la Iglesia y la sociedad sobre este tema y se critica a ambas partes: a la Iglesia por su rigor, a la cultura por su desregulación casi total de la vida sexual. Se pide que ambas se acerquen sobre estos temas que se relacionan con el sentido y el significado de la sexualidad. Se advierte también que demasiadas pocas voces matizadas se atreven a expresarse en el seno de la comunidad eclesial porque estos temas son sensibles dentro de la Iglesia. La visión de HV/la Iglesia sigue demasiado alejada de la esfera de vida de los jóvenes (CENTRO TEOLÓGICO MANUEL LARRAÍN, 2014, p. 34).

La Conferencia episcopal francesa insiste también que para la gran mayoría de las respuestas, la $H V$ ha tenido como consecuencia que muchas parejas rompan con las enseñanzas de la Iglesia. La insistencia de la Iglesia en este punto parece incomprensible para muchos católicos. Una pequeña minoría más convencida aplica estas enseñanzas inspirándose por ejemplo en el método Billings. Lo que espera la mayoría de la Iglesia son criterios de discernimiento que les sirvan de puntos de referencia.

La Conferencia de obispos suizos señala la "distancia dramática y conocida desde hace largo tiempo, entre la doctrina y los participantes en la consulta. La prohibición de los métodos artificiales de contracepción está muy lejos de la práctica y de las ideas de la gran mayoría de los católicos" (CENTRO TEOLÓGICO MANUEL LARRAÍN, 2014, p. 60).

De estas voces que recogen los episcopados puede deducirse una experiencia concreta que es compartida por muchos católicos en Europa y América, experiencia que ya había expresado claro y alto el Cardenal Martini. Distancia, lejanía, incomprensión son palabras que se repiten. No por todos, pero sí por bastantes de ellos. Sólo quizás una minoría, que podría estar en torno al 3\%, en la que se insertan sólo los que pertenecen a ciertos grupos eclesiales, podría ser la que vive gozosamente el mensaje completo de la $\mathrm{HV}$ y los métodos naturales.

\section{b) La voz más plural del sínodo del sínodo: laicos y obispos}

En el Sínodo extraordinario, fue precisamente la pareja brasileña de auditores de los Equipos de Nuestra Señora, Arturo y Hermelinde As Zam- 
berline, los que afirmaron el 9 de octubre de 2014 que "dada la gravedad del entorno en que nos encontramos debemos admitir sin miedo que la mayor parte de las parejas católicas, incluso aquellos que quieren vivir su matrimonio en serio, no se sienten obligados a seguir esas instrucciones, ni consideran la anticoncepción un problema moral o un pecado a confesar".

La mayoría de las parejas no hablaron en el Sínodo de la anticoncepción artificial. Una excepción fue la intervención de Sharon Cole, Presidenta de los Parents Centres de Nueva Zelanda que expresó claramente la necesidad de reexaminar la enseñanza del matrimonio y la sexualidad de la $H V$ y reconocer cómo para muchas parejas no es practicable. Los métodos naturales son sólo efectivos para parejas motivadas pues la mayoría tienen dificultades que les llevan durante un tiempo a usar anticonceptivos artificiales en el ejercicio de su paternidad responsable. De nuevo aparecía una mayoría con dificultades y una minoría motivada.

María Gomez, responsable de la pastoral familiar parroquial en Dubai, reconoció tangencialmente que los estilos de vida hacen que se encuentre la planificación familiar natural tediosa y la procreación sea pospuesta por el uso de contraceptivos. Otras intervenciones abogaron por la formación en los métodos naturales o por la verdad de la HV. En cualquier caso, los laicos que acudieron al Sínodo ordinario y extraordinario no fueron representativos del laicado católico medio en estos temas (DE LATORRE, 2018, p. 261-262).

Con todas las respuestas recibidas se elaboró el Documento de trabajo (Instrumentum laboris) del Sínodo que reconoció "una distancia preocupante entre la familia, entre las formas como se la conoce hoy, y la enseñanza de la Iglesia al respecto" (n. 31) sobre todo en aspectos como el "control de los nacimientos, el divorcio y las nuevas nupcias, la homosexualidad, la convivencia, la fidelidad, las relaciones prematrimoniales, la fecundación in vitro y la aceptación integral del magisterio de la Iglesia sobre la ley natural" (n. 13).

El Instrumentum laboris señaló que la encíclica $H V$ tuvo un significado claramente profético al subrayar la unión inquebrantable entre el amor conyugal y la transmisión de la vida (n. 122) pero, en la mayoría de los casos, no se conoce su dimensión positiva (n. 123).

Quienes afirman que la conocen pertenecen casi siempre a asociaciones y grupos eclesiales que frecuentan las parroquias o participan activamente en caminos de espiritualidad familiar. En la gran mayoría de las respuestas, se pone de relieve que hoy la mentalidad común percibe como una injerencia en la vida íntima de la pareja y una limitación a la autonomía de la conciencia la valoración moral de los diferentes métodos de regulación de matrimonios (ibid., n.123).

Además "cuesta entender la distinción entre los métodos naturales de regulación de la fertilidad y la contracepción y los métodos naturales se consideran 
simplemente ineficaces e impracticables" (ibid., n. 124). Finalmente es consciente de la "enorme brecha entre la doctrina de la Iglesia y la sociedad civil" (ibid., n. 126).

Como afirma el cardenal Kasper (2018, p. 22): "Muchos cristianos no pueden comprender ya algunos aspectos de la moral sexual, matrimonial y familiar de la Iglesia. A nadie con experiencia pastoral le sorprendió ese resultado".

En la Relatio ante disceptationem (6.10.2014) no se habló explícitamente del tema. Se señala que es importante proponer de forma positiva el mensaje de la HV a través de una hermenéutica histórica adecuada. Se citan las famosas palabras de Pablo VI del 31-7-1968 de que la $H V$ "no es una exposición completa de todo lo relativo al ser humano en el campo del matrimonio" y que la Iglesia "podrá volver con un designio más amplio, orgánico y sintético". También se cita la ley de la gradualidad (FC, n. 34). El Sínodo opta por no centrarse en este tema y ofrecer criterios a la Iglesia y los fieles.

En la Relatio post-disceptationem se apunta a que "es necesario un lenguaje realista, que sepa comenzar por la escucha de las personas y que sepa dar razones de la belleza y de la verdad de una apertura incondicionada a la vida...Y sobre esta base se puede apoyar una enseñanza adecuada acerca de los métodos naturales, que permita vivir de manera armónica y consciente la comunicación entre los esposos, en todas sus dimensiones, junto a la responsabilidad generativa. En esta luz, se redescubre el mensaje de la $H V$ que subraya la necesidad de respetar la dignidad de la persona en la evaluación moral de los métodos de regulación de la natalidad" (n. 54).

En la Relatio Synodi no hay cambios en este tema. El Sínodo pareció dejar a un lado esta cuestión. No era lo que más preocupaba a la mayoría de los congregados. Fueron contadas las ocasiones en que se hizo referencia a la $H V$ y con diferentes tonalidades y acentos. El tono predominante, en cualquier caso, era más positivo e integrador, menos normativo.

\section{c) La voz del papa Francisco: la Amoris laetitia}

Escuchar. La voz del papa es la última en hablar. Primero realiza una consulta y escucha a los fieles y a la Iglesia entera. Luego escucha al Sínodo. Lo que llama la atención de este papa en el Sínodo es que sobre todo $\mathrm{y}$ ante todo ha escuchado. Es un magisterio oyente de la palabra de los fieles y los obispos, de la tradición, de la liturgia, de la fe del pueblo de Dios. Estamos en las antítesis de Pío X. Francisco, con Evangelii gaudium y Amoris laetitia, ofrece una nueva comprensión del papado dentro de una Iglesia de comunión en la que el papado no siempre debe ofrecer una palabra definitiva y completa $(A L, \mathrm{n} .3 ; E G, \mathrm{n}$. 16). El papado se presenta más humilde, más limitado, más menguante, para dejar que otros crezcan, para que se escuchen otras voces. 
Francisco en $A L$ cita 133 veces el Sínodo. FC sólo lo hizo en dos ocasiones. En los temas de la anticoncepción y la $H V$, Francisco remite casi siempre a lo aprobado por el Sínodo. En las cuestiones debatidas, prefiere estar al lado de lo aprobado por el Sínodo. En muchas ocasiones, deja su reflexión y prefiere apoyarse en las reflexiones de las diversas conferencias episcopales del mundo. EG y $A L$ esbozan las líneas fundamentales de un nuevo paradigma menos normativo, menos paternalista y jerárquico y más atento al discernimiento propio de los fieles y de las conferencias episcopales.

Nuevas palabras centrales. Las palabras usadas en el diálogo son distintas y diferentes en su significado: conciencia, discernimiento, camino, gradualidad, acompañamiento, integración, misericordia, fragilidad, vulnerabilidad, ternura, complejidad y alegría. Otras palabras son reformuladas. Ya no se habla de situaciones irregulares sino de situaciones imperfectas. Algunas palabras son evitadas como intrínsecamente malo-deshonesto (CC), objetivamente contradictorio $(F C)$, ley natural $(H V)$, norma canónica. No se rechazan sino que se integran en una totalidad mayor donde adquieren un papel secundario y un sentido más hondo. La ley natural, tan importante en la $H V$, es simplemente referida a través de un documento de la Comisión Teológica Internacional y el problema de su historicidad y aplicabilidad a los contextos concretos: no debe entenderse como "un conjunto ya constituido de reglas que se imponen a priori al sujeto moral". Es más bien una "fuente de inspiración objetiva", una brújula interna, una voz interior.

Lenguaje positivo y propositivo. El lenguaje sobre lo humano es positivo y luminoso $(A L$, n. $67,142-152)$. "Por algo será que un amor sin placer ni pasión no es suficiente para simbolizar la unión del corazón humano con Dios" ( $A L, \mathrm{n} .142)$. "Dios mismo creó la sexualidad que es un regalo maravilloso para sus criaturas" ( $A L, \mathrm{n}$. 150). La dimensión erótica del amor es como un "don de Dios que embellece el encuentro de los esposos" ( $A L$, n. 152). Los deseos, sentimientos, emociones tienen un lugar importante en el matrimonio (n. 143).

Postconciliar. Francisco en su diálogo y escucha no quiere dejarse enredar por cuestiones y debates del pasado que ya a casi nadie importan hoy. Las urgencias de hoy deben marcar el anuncio de la Iglesia. Hay una ausencia de la teología preconciliar y del Magisterio de Pío XI (CC) y Pío XII tan influyentes en los debates de GS y $H V$. Sólo hay referencias colaterales y poco relevantes en $A L, \mathrm{n} .75 \mathrm{y}$ n. 215. Es significativo que cuando en la tercera parte habla de la doctrina de la Iglesia sobre el matrimonio y la familia comienza en el Concilio Vaticano II. En este sentido podemos afirmar que $A L$ supone la superación de una teología y una eclesiologías pianas (desde Pío VII a Pío XII).

Hermenéutica y antropología más amplia, orgánica y sintética. Siguiendo las palabras de Pablo VI, el 31 de julio de 2018, Francisco aborda estos temas desde una hermenéutica más amplia, más bíblica, más realista, más orgáni- 
ca, más social y más cultural. El núcleo esencial de este nuevo paradigma que empieza a diseñarse es la referencia a la persona y lo interpersonal. Francisco en $A L$ dialoga sin rubor con la filosofía, la literatura, el cine, la sociología, la psicología más que con la ley natural. La intuición fundamental del papa es que cada persona, en cada situación, por muy compleja que sea, es alcanzada y atraída por Dios que le ofrece siempre un camino para acercarse y unirse más a él (EG, n. 112-113).

Hermenéutica más social y política. Bergoglio está atento a las dificultades y condicionamientos sociales y económicos, a los valores concretos, más que a las normas e ideales abstractos. La moral sexual que aparece en la $A L$ está profundamente vinculada a dimensiones sociales y políticas: la educación de las emociones y la educación sexual ( $A L$, capítulo VII), la crítica al individualismo y hedonismo de nuestra cultura. La fecundidad es comprendida dentro de un concepto de fecundidad ampliada ( $A L$, capítulo V) que no está centrado en el lecho conyugal sino en el amor de la pareja, en el proyecto de pareja, en la vida amplia de la familia, de la sociedad y de la Iglesia con una preocupación especial por los más vulnerables.

Propuesta de criterios. La presencia de la $H V$ en $A L$ se encuentra en seis números $(68,80,82,154,167,222)$. En estos números, $A L$ recupera de $H V$ los criterios centrales de GS, n. 50 más que la norma de $H V$, n. 14 . Francisco habla más de orientaciones-criterios que de normas y actos concretos en sus referencias a la $H V$. "Un pastor no puede sentirse satisfecho solo aplicando leyes morales (...) como si fueran rocas que se lanzan" (n. 304). En las seis referencias a $H V$ en $A L$ hay referencias a los criterios de respeto, dignidad, conciencia, decisión mutua (no imposición), apertura, generosidad, paternidad responsable, rechazo de una mentalidad hostil a la vida y estímulo para promover los métodos naturales.

Centralidad del amor. Francisco, siguiendo a Benedicto XVI y su reflexión en Deus caritas est, con $A L$ pone en el centro el amor y profundiza en su sentido. Al es todo un tratado sobre el amor mutuo. No es el amor romántico sino el amor en transitivo, a otra persona concreta en una situación concreta y limitada. El papa recoge las aportaciones del Aquinate, Sertillanges, Marcel, Pieper, Fromm. La cuarta parte, de una finura psicológica inigualable en el Magisterio, puede ser leída con gozo por la mayoría de los seres humanos. La palabra del Magisterio en estos temas acompaña las búsquedas sobre lo que significa amar en este mundo difícil a tantas personas ordinarias y puede ser una luz que les acompaña en sus dificultades. Es un diálogo profundo con las personas hoy sobre lo que significa amar. No hay nada de imposición, sino de conversación de corazón a corazón.

AL parte más de lo común y compartido que de las diferencias. Hay unos criterios compartidos que son subrayados en $A L$ y que vienen de GS y Sínodo. Hay una remisión a los ámbitos más de comunión. El papa es consciente 
de que hay una recepción clara de la mayoría de los fieles y pastores de $H V$, n. 10-13. Francisco busca subrayar lo que une, la comunión. Estos números forman un rico patrimonio. Por eso $A L$ es resultado de un proceso de consenso en la Iglesia y de realización de la sinodalidad.

AL subraya la continuidad con lo mejor a la HV. AL profundiza, enriquece y amplia muchos aspectos de la $H V$ : el sentido del amor, de la fecundidad, de la unión de la sexualidad con la procreación, de la paternidad responsable, del coraje de resistir a los condicionamientos políticos y económicos en la planificación familiar, de elegir en conciencia, de ser generosos con la vida, de rechazar una cultura hedonista que margina la vida de los más vulnerables, de la fecundidad ampliada, etc. Hay un mensaje positivo en la $H V$ que está en el corazón de muchos cristianos y personas de buena voluntad.

AL integra y escucha las dificultades de los fieles. Algunas conferencias episcopales en 1968 y en 2014 expresaron, como hemos visto, las dificultades de los fieles en la recepción de la norma de la $H V$, n. 14. Las Conferencias Episcopales en 1968 realizaron una hermenéutica integradora del Magisterio papal con las inquietudes de los fieles a través de la reivindicación de la conciencia y de principios como el de conflicto de deberes y valores o el principio del mal menor (DE LA TORRE, 2018, p. 485-534). La superación del paradigma normativo-ideal en sociedades complejas y en cambio, le hace al papa reconocer que en situaciones complejas es difícil encontrar una norma universal ( $A L$, n. 298). Como afirma el papa Francisco en su última exhortación Gaudete et exultate:

las preguntas de nuestro pueblo, sus angustias, sus peleas, sus sueños, sus luchas, sus preocupaciones, poseen valor hermenéutico que no podemos ignorar si queremos tomar en serio el principio de encarnación. Sus preguntas nos ayudan a preguntarnos, sus cuestionamientos nos cuestionan (n. 44).

Muchos católicos han hecho su discernimiento propio en estos temas hace tiempo. No hay una recepción clara de la doctrina de $H V, \mathrm{n} .14$ en la mayoría de los católicos. $H V$, n. 14 hoy no representa la totalidad de la doctrina católica. Francisco integra otros caminos e interpretaciones desde las voces de los fieles y las conferencias episcopales (1968 y 2014). Francisco reconoce que los fieles desde su conciencia "muchas veces responden lo mejor posible al Evangelio en medio de sus limitaciones y pueden desarrollar su propio discernimiento ante situaciones donde se rompen todos los esquemas" ( $A L$, n. 37).

AL expresa un silencio elocuente sobre la anticoncepción artificial. El Sínodo y $A L$ guardan silencio sobre la anticoncepción artificial para insistir en los elementos centrales de la doctrina. Este silencio es un silencio discernido, pensado, respetuoso que quiere ser luz para un tema eclesialmente debatido desde hace ya más de cincuenta años. $A L$ ofrece una interpretación 
amplia de $H V$ como pedía Pablo VI y permite afirmar que hoy la norma de la $H V$, n. 14 no representa toda la totalidad de la doctrina católica, pues sólo para "minorías íntimamente convencidas", la mayoría pertenecientes a ciertos grupos eclesiales, es una buena nueva. El silencio sobre los métodos y su apertura de procesos de discernimiento es su propuesta concreta de paternidad responsable desde una conciencia responsable y respetuosa con el otro. Francisco a esas parejas no les da una "nueva" norma sino que les abre un camino, una puerta, un proceso. La solución no es una norma ni una nueva norma. Lo moral no puede reducirse a una norma. La solución es respetar el discernimiento responsable de la conciencia y saber guardar silencio en lo que no es fundamental.

AL manifiesta un espíritu que reconcilia la diversidad. El Espíritu es el que puede unir lo diverso, ayudar a vivir en unidad en la diversidad, a vivir en una diversidad reconciliada $(A L, \mathrm{n}$. 139) en un tema como el abordado por la Humanae vitae. El Espíritu renueva a la Iglesia desde dentro y en mitad de su caminar, en distintas épocas y documentos, señalando diferencias de acento y desarrollo. En la Iglesia nada quede concluido, ni petrificado, ni solidificado, ni por un Concilio ni por un determinado pontificado. El Espíritu Santo nos guía hacia la verdad plena hasta el final de los tiempos (Jn 16, 13). Con el pontificado del papa Francisco se ha iniciado una nueva fase de la recepción del Concilio y de los pontificados anteriores para transmitir al futuro con fidelidad creadora lo recibido (KASPER, 2018, p. 29-31). Esa fuente fresca del Espíritu es la que está soplando en los dos últimos sínodos y en la AL cuando habla de recalcar lo central, lo que nos une y de guardar silencio en lo que no está maduro o no ha sido recibido por los fieles.

\section{Conclusión: hacia un nuevo de hablar hoy la Iglesia}

Hemos visto los distintos tipos de diálogos y silencios en torno a este tema en los últimos cincuenta años: diálogos abiertos, diálogos en búsqueda, diálogos integradores, diálogos interrumpidos, diálogos limitados, diálogos más amplios, silencios queridos, silencios impuestos, silencios elocuentes, etc. Hemos terminado este recorrido con ese acontecimiento dialogal y ejemplo privilegiado de lo que puede significar la sinodalidad que es Amoris laetitia. AL que nos sugiere nuevos modos de diálogo comenzando por el valor de la escucha, las palabras nuevas, las palabras positivas, la necesidad de ir a lo central del amor, a lo compartido y lo que integra a todos respetando con un cuidadoso silencio los discernimientos de la mayoría del pueblo de Dios.

La moral sexual es el ámbito de la Iglesia más separado de la vida de los seres humanos en nuestros países occidentales. En estos temas a los 
jóvenes (y a muchos adultos), a veces, les parece estar escuchando palabras de otro planeta, poco razonables y plausibles cuando la moral sexual se concreta en normas detalladas. La convivencia prematrimonial frecuente, las relaciones sexuales tempranas junto con el retraso del matrimonio, los nuevos anticonceptivos orales y hormonales, el uso frecuente de la pornografía, una valoración positiva de la sexualidad y la afectividad, han cambiado enormemente en estos cincuenta años nuestra opciones de vida y vivencias sacramentales. Las parejas cristianas comprometidas que hoy conocen la $H V$, n. 14 no viven la prohibición de la anticoncepción artificial como un desafío a sus conciencias sino más bien como un interrogante hacia la misma Iglesia por mantener una doctrina tan detallista, tan casuística en el lecho conyugal.

Los cincuenta años de $H V$ son una buena oportunidad para aprender a hablar de moral sexual hoy en la Iglesia. Escuchar, acercarse, evangelio, acompañar, criterios, aliento de crecimientos, positividad, respeto a las conciencias, silencio, ayudar a discernir y ponderar junto con otros. Es hora de hacer una hermenéutica más amplia, orgánica y sintética, como pedía el mismo Pablo VI el 31 de julio de 1968 y ha realizado tan magistralmente el papa Francisco en $A L$. Hay que dejar las guerras de nuestros antepasados, volver al patrimonio que nos une y saber guardar silencio sobre algunas cuestiones secundarias respetando diversos caminos. Unidad en lo necesario, libertad en lo opinable y caridad en todo, como nos recuerda la frase atribuida a San Agustín. Después de cincuenta años de la $H V$ y una más profunda escucha a la Palabra, al Espíritu, al pueblo de Dios, a las Conferencias Episcopales, a los obispos, al Magisterio papal y a los dos últimos Sínodos, tenemos que aprender en los temas de moral sexual a escuchar, guardar silencio, hablar mejor y dialogar. No son palabras retóricas. Es una realidad: todavía tenemos un gran camino en nuestro aprender a escuchar, callar y dialogar.

\section{Siglas}

AAS = Acta Apostolicae Sedis

$\mathrm{AL}=$ Exhortación Apostólica Postsinodal Amoris Laetitia

CC = Carta encíclica Casti Connubii del Papa Pío XI sobre el matrimonio cristiano

CELAM = Consejo Episcopal Latinoamericano

$\mathrm{EG}=$ Exhortación Apostólica Evangelii Gaudium

FC $=$ Exhortación Apostólica Familiaris Consortio

GS = Constitución Pastoral Gaudium et Spes sobre la Iglesia en el mundo actual

$\mathrm{HV}=$ Carta encíclica Humanae Vitae de S. S. Pablo VI 


\section{Referencias}

AA.VV. Control de natalidad. Informe de expertos: los documentos de Roma. Madrid: Alameda, 1967.

ALBERIGO, G. Historia del Concilio Vaticano II. Salamanca-Leuven: Sígueme-Peeters, 2007. t. IV.

BENEDICTO XVI, Papa. Encíclica Deus caritas est 2015.

Discurso a los participantes en el Congreso organizado por la Pontificia Universidad Lateranense en el XL aniversario de la encíclica Humanae vitae (10 de mayo de 2008). Ecclesia, Madrid, n. 3/419, p. 27-28, 2008.

. Luz del mundo: el papa, la Iglesia y los signos de los tiempos (una conversación con Peter Seewald). Barcelona: Herder, 2010.

Últimas conversaciones con Peter Seewald. Bilbao: Mensajero, 2016.

CENTRO TEOLÓGICO MANUEL LARRAÍN. Los desafíos pastorales sobre la familia en el contexto de la evangelización. Sínodo de los Obispos. Traducción al español de las respuestas a las 39 preguntas de las Iglesias en Alemania, Bélgica, Francia, Japón y Suiza. Santiago de Chile: Centro teológico Manuel Larraín, 2014.

DE LA TORRE, J. Humanae vitae 14: una propuesta desde Amoris laetitia. Santander: Sal terrae, 2018.

FRANCISCO, Papa. Exhortación apostólica Amoris laetitia del Santo Padre Francisco [...] sobre el amor en la familia. Madrid: San Pablo, 2016.

HAMEL, E. Para una reflexión católica sobre la encíclica Humanae vitae. Qué piensa en realidad el episcopado católico sobre la Humanae vitae. Theologia Xaveriana, Bogotá, v. 19, n. 21, p. 48-134, 1969.

HEBBLETHWAITE, P. Pablo VI: el primer papa moderno. Buenos Aires: Javier Vergara editor, 1995.

JUSTICIA Y PAZ SUIZA. L'AIDS è una sfida per tutti. Il Regno, Bologna, v. 33, n. 18, p. 592, 1988.

KASPER, W. El mensaje de Amoris laetitia: un debate fraterno. Santander: Sal terrae, 2018.

MARTINI, C. M. Coloquios nocturnos en Jerusalén. Madrid: San Pablo, 2008.

MCCORMICK, R. Humanae vitae 25 Years Later. America, v. 169, n. 2, p. 6-12, July 1993.

MIFSUD, T. Decisiones responsables: una ética del discernimiento. Santiago de Chile: Ediciones Universidad Alberto Hurtado, 2012.

MOSER, A. Planejamento familiar na Igreja Católica: do ruído estrondoso a um silêncio perturbador, In: SANCHES, M. A (Org.). Bioética e planejamento familiar: perspectivas e escolhas. Petrópolis: Vozes, 2014. p. 59-70.

O’MALLEY, J. W. ¿Qué paso en el Concilio Vaticano II? Santander: Sal Terrae, 2012.

PÍO X, Papa. Vehementer Nos. Epistola encyclica SS. D. N. PII Div. Prov. PP X. 11 de Febrero de 1906. 
RATZINGER, J. Ser cristiano en la era neopagana. Madrid: Encuentro, 1995.

SIMÓN VÁZQUEZ, C. Estudio histórico-crítico del concepto y del término de Planificación Familiar. Murcia: Fundación Universitaria San Antonio, 2004.

SPADARO, A. Entrevista al papa Francisco. Disponible en: <https://w2.vatican.va/ content/francesco/es/speeches/2013/september/documents/papa-francesco_20130921_ intervista-spadaro.html>.

ZALBA, M. Las conferencias episcopales ante la Humanae vitae. Madrid: Cio, 1971.

Artículo sometido en 30.05.2018 y aprobado en 10.07.2018.

Francisco Javier de La Torre Díaz es Doctor en Derecho y Licenciado en Filosofía y Teología Moral por la Universidad Complutense, Madrid (1999). Director Cátedra Bioética y del Máster Bioética. Profesor de Teología Moral. Orcid.org/0000-0003-2995-6594. Correo electrónico: jtorre@comillas.edu

Dirección: Universidad Comillas, 3

28049 Madrid, España 